\title{
Pengembangan E-Modul Berbasis Kontekstual pada Materi Program Linear Kelas XI
}

\author{
Reny Eka Nur Afrianti, Abd. Qohar
}

(C) 2019 JEMS (Jurnal Edukasi Matematika dan Sains)

This is an open access article under the CC-BY-SA license (https://creativecommons.org/licenses/bysa/4.0/) ISSN 2337-9049 (print), ISSN 2502-4671 (online)

\begin{abstract}
Abstrak:
Penelitian ini bertujuan untuk mengembangkan modul berbasis elektronik (E-Modul) pada materi program linier dengan menggunakan masalah yang kontekstual. E-Modul yang dikembangkan merupakan modul berbasis android. Respoden penelitian ini adalah siswa kelas XI SMA Negeri 1 Talun. Media dikembangkan dalam tiga tahap. Tahap pertama adalah tahap analisis produk yang dikembangkan yaitu terdiri dari analisis concept, design, dan collecting materials. Tahap kedua adalah tahap mengembangkan produk awal yaitu terdiri dari pembuatan power point yang kemudian di-upload dalam program web to apk. Saat pengembangan produk gambar dan animasi yang dipilih disesuaikan dengan usia siswa sekolah menengah agar konsep mudah dipahami siswa. Produk dibuat dengan mengangkat cerita kontekstual dalam kehidupan sehari-hari yang dipahami siswa sekolah menengah. Tahap ketiga adalah uji coba produk yang terdiri dari uji ahli dan uji coba skala kecil. Uji ahli terdiri dari validasi media dan validasi materi. Hasil menunjukkan bahwa media pembelajaran E-Modul yang dikembangkan valid dan praktis. Nilai kevalidan yang diperoleh yaitu nilainya 3,2.
\end{abstract}

Kata Kunci : E-modul; Kontekstual; Program Linear

\begin{abstract}
:
This study aims to develop electronic-based modules (EModules) in linear program material using contextual problems. The developed e-module is an android-based module. The respondents of this study were students of class XI of SMA Negeri 1 Talun. The media developed in three stages. The first stage is the product analysis stage, which is developed, which consists of the analysis of concepts, design, and collecting materials. The second stage is the stage of developing the initial product, which consists of making powerpoints that are then uploaded on the web to an application program. When developing selected drawing and animation products, it is adjusted to the age of secondary school students so that the concepts are easily understood by students. Products are made by bringing up contextual stories in everyday life that are understood by middle school students. The third stage is product trials consisting of expert trials and small scale trials. Expert tests consist of media validation and material validation. The results show that the E-Module learning media developed are valid and practical. The validity value obtained is 3.2 .
\end{abstract}

Keywords : E-module; Contextual; Linear Program

\section{Pendahuluan}

Matematika merupakan salah satu bidang ilmu yang penerapannya sering digunakan untuk memecahkan masalah dalam kehidupan sehingga penting untuk dipelajari (Subanji, 2015). Uno (2018) menambahkan bahwa dengan belajar matematika sesorang akan berlatih untuk berpikir dan memecahkan masalah seperti logika, penalaran, dan konstruksi pengetahuan. Pendapat serupa dengan Mulyana (2004) yang menjelaskan bahwa dengan belajar matematika seseorang dapat menambah pengetahuan, wawasan, cara berpikirnya lebih logis dan terstruktur baik dalam menyelesaikan masalah matematis maupun bidang ilmu lain dalam kehidupan. Kenyataannya kemampuan siswa dalam pemecahan masalah masih kurang (Serhan, 2015; Dorko, 2013; Booth, 2014; Veloo, 2015, Kamber, 2018). 
Salah satu materi matematika yang sering diterapkan dalam kehidupan yaitu program linier. Permendikbud No. 24 Lampiran 16 Tahun 2016 menyebutkan bahwa siswa sekolah menengah kelas XI diharapkan dapat menjelaskan program linier dua variabel dan metode penyelesaiannya dengan menggunakan masalah kontekstual. Materi program linier merupakan salah satu standar konten menurut NCTM (2000) yaitu aljabar. Sebab program linier menggunakan model matematika dalam menyajikan dan menganalisis situasi dan strukturnya melalui simbol-simbol aljabar Kennedy (2008). Oleh karena itu materi program linier penting dipelajari siswa sekolah menengah. Namun kemampuman siswa mengenai materi program linier masih kurang (Hidayat, 2015; Septian, 2016).

Sejalan dengan hal tersebut agar materi program linier dapat dikuasai siswa dengan mudah perlu adanya media pembelajaran yang dapat memberikan motivasi belajar siswa. Media pembelajaran dapat meningkatkan pemahaman siswa (Ariawan, 2015; Putra, 2015; Setyadi, 2017; Arsyad, 2015; Afgani, 2008; Dabbagh, 2012; Greenhow, 2016; Zuana, 2018). Media adalah segala sesuatu yang dapat menyalurkan informasi dari sumber informasi kepada penerima informasi. Media pembelajaran berbasis android perlu dikembangkan mengingat telepon genggam (handphone) merupakan alat komunikasi yang saat ini sangat diminati siswa sekolah menengah.

Disisi lain sebagai upaya dalam memberikan layanan pendidikan yang efektif, efisien, dan maksimal terhadap kemajemukan potensi siswa perlu diterapkannya sistem kredit semester (Muhlis, 2017). Berdasar-kan Permendikbud nomor 158 tahun 2014 tentang penyelenggaraan Sistem Kredit Semester (SKS) menyatakan bahwa pada jenjang SMP/MTs dan SMA/SMK/MA/ MAK dapat menyelenggarakan sistem SKS. Sistem SKS adalah bentuk penyelenggaraan pendidikan yang peserta didiknya menentukan jumlah beban belajar dan mata pelajaran yang diikuti setiap semester pada satuan pendidikan sesuai dengan bakat, minat, dan kemampuan atau kecepatan belajar. Salah satu produk dari SKS ini adalah unik kegiatan belajar mandiri (UKBM). UKBM ini menggunaannya mirip dengan modul. Berdasarkan uraian diatas perlu dikembangkan media pembelajaran modul berbasis elektronik dengan telepun genggam pada materi program linier. Oleh karena itu penulis akan melakukan penelitian yang berjudul "Pengembangan E-Modul Berbasis Kontekstual pada Materi Program Linier Kelas XI"

\section{Metode}

Penelitian dilaksanakan di SMA Negeri 1 Talun pada bulan April 2019 pada kelas 11 MIPA. Penelitian ini merupakan penelitian pengembangan. E-Modul ini dikembangkan melalui 3 tahapan. Tahapan tersebut adalah analisis produk yang dikembangkan, mengembangkan produk awal, dan uji coba produk. Tahap analisis produk yang dikembangkan terdiri dari analisis concept, design, dan collecting materials. Tahap mengembangkan produk awal diawali dengan membuat materi program linier pada microsoft office power point yang dilengkapi dengan program I-Spring. Setelah di-upload pada program I-Spring diproses pada program web to apk. Uji coba produk dalam penelitian ini terdiri dari validasi ahli, uji coba dalam skala kecil, dan revisi produk. Validasi meliputi validasi produk dan validasi materi dari validator yaitu dosen S2 Pendidikan Matematika Universitas Negeri Malang.

\section{Hasil dan Pembahasan}

a. Analisis Produk yang Dikembangkan

Analisis produk yang dikembangkan terdiri dari analisis concept, design, dan collecting materials. Pada tahap analisis concept, dilakukan analisis terhadap hal-hal yang diperlukan dalam 
perencanaan perangkat pembelajaran. Materi yang digunakan pada tahap ini adalah program linier.

Pada tahap analisis design, peneliti membuat rancangan tentang tampilan E-Modul yang akan dikembangkan. Peneliti merencanakan menu-menu utama, sub menu yang akan ditampilkan, tema, animasi, dan gambar.

Pada tahap collecting materials, peneliti mengumpulkan bahan yang diperlukan untuk membuat produk. Peneliti membuat materi yang akan dikembangkan pada E-Modul yang meliputi pemilihan masalah kontekstual yang membangun konsep program linier, pembuatan grafik dan gambar-gambar melalui progam lain yang mendukung yang dapat diinstal di handpone android.

b. Mengembangkan produk awal

Mengembangkan produk awal diawali dengan membuat power point yang berisi konsepkonsep materi program linier. Power point ini dilengkapi dengan menu-menu yang di-hiperlink ke submenu selanjutnya. Gambar-gambar dan animasi yang mendukung konsep program linier serta sesuai dengan usia anak sekolah menengah.

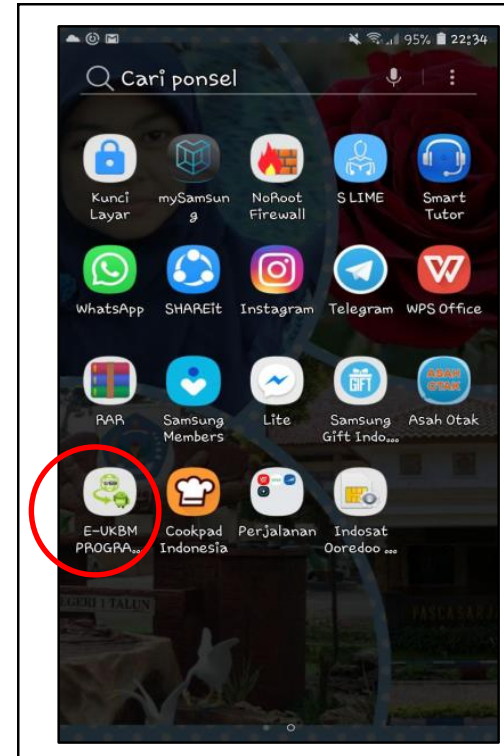

Gambar 1a

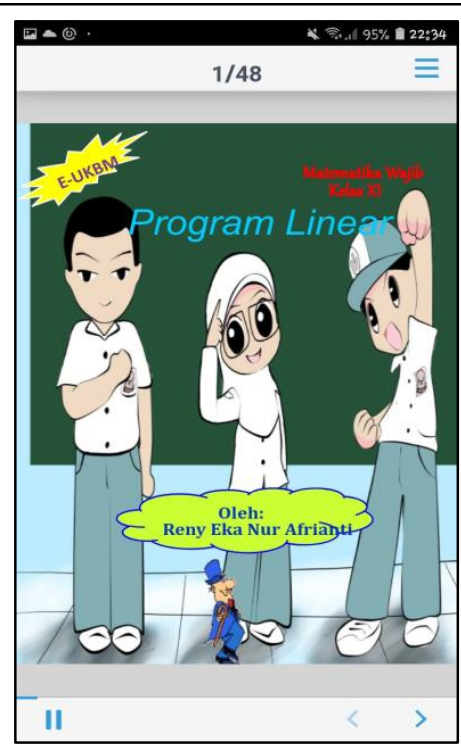

Gambar 1b

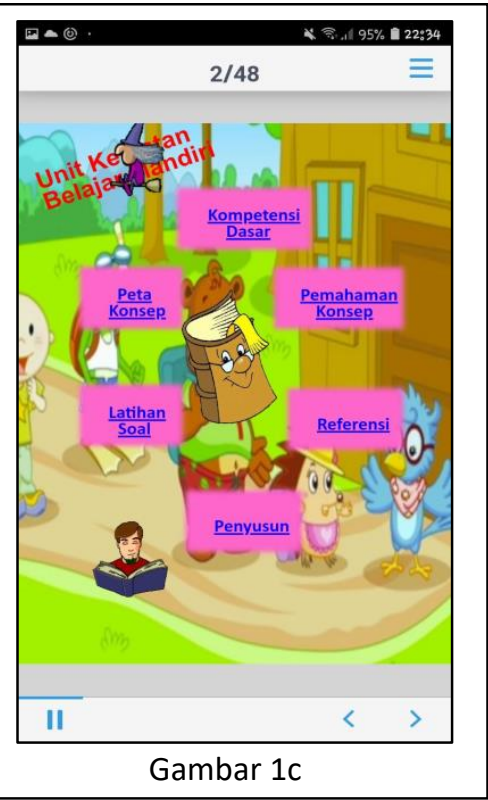

Gambar 1c

Gambar 1. Icon E-Modul pada hanphone (1a), sampul E-Modul (1b),

dan menu E-Modul (1c)

Gambar 1a merupakan tampilan aplikasi E-Modul program linier dalam handphone. Icon untuk E-Modul ini dapat diganti sesuai dengan tema yang diinginkan menggunakan gambar tipe PNG. Gambar 1b merupakan tampilan pertama atau sampul dari E-Modul. Tampilan pertama sengaja diberikan gambar kartun anak SMA/MA untuk menegaskan bahwa media ini untuk anak SMA/MA. Pada sampul ini diberikan animasi agar tampilan pertama menarik. Gambar 1c merupakan pilihan menu. Pilihan menu yang diberikan ada 6 pilihan. Menu yang disediakan diantaranya menu kompetesi dasar yang berisi KD program linier yang dibahas pada media ini, peta konsep berisi alur pembelajaran program linier, pemahaman konsep yang berisi materi kontekstual dalam pembelajaran program linier, latihan soal yang terdiri 5 soal uraian, referensi yang berisi daftar pustaka dari pembuatan media ini, dan penyusun yang berisi biodata pembuat media ini. Setiap menu apabila ditekan akan mengarah ke penjelasannya masing-masing. 


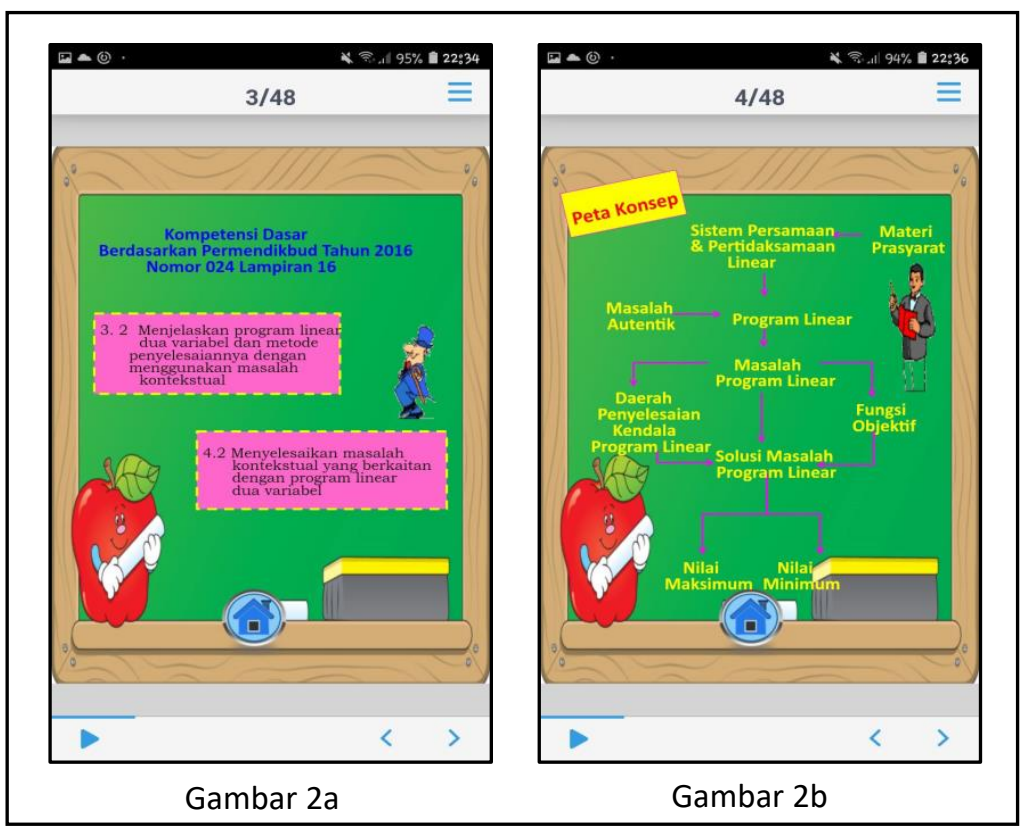

Gambar 2. Submenu KD (2a) dan submenu peta konsep (2b)

Gambar 2a merupakan tampilan submenu kompetensi dasar (KD) program linier sesuai dengan Permendiknas No. 24 Lampiran 16. Gambar 2b merupakan peta konsep alur dari materi program linier mulai dari materi prasyarat hingga penggunakan materi program liniear dalam kehidupan.

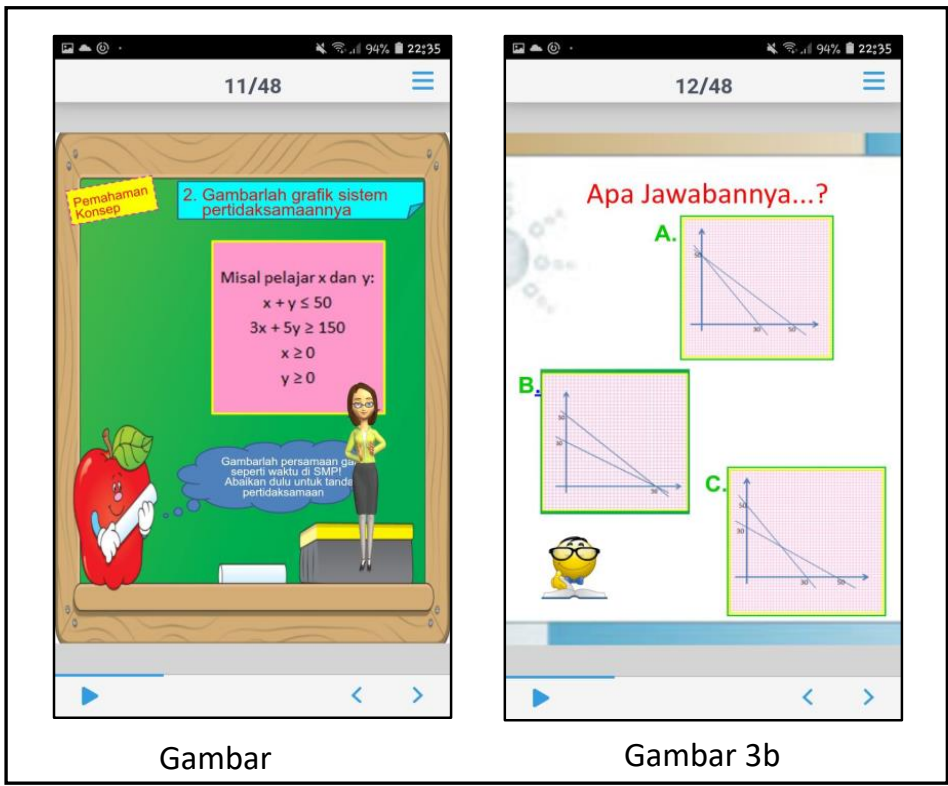

Gambar 3. Halaman pemahaman konsep (3a) dan pilihan jawaban konsep (3b)

Gambar 3a merupakan salah satu halaman pemahaman konsep. Halaman ini masih di-hiperlink ke pertanyaan dan jawaban yang mendukung proses kontruktivisme konsep. Gambar 3a animasinya memunculkan pertanyaan. Kemudian akan muncul 3 pilihan jawaban seperti gambar $3 b$ 


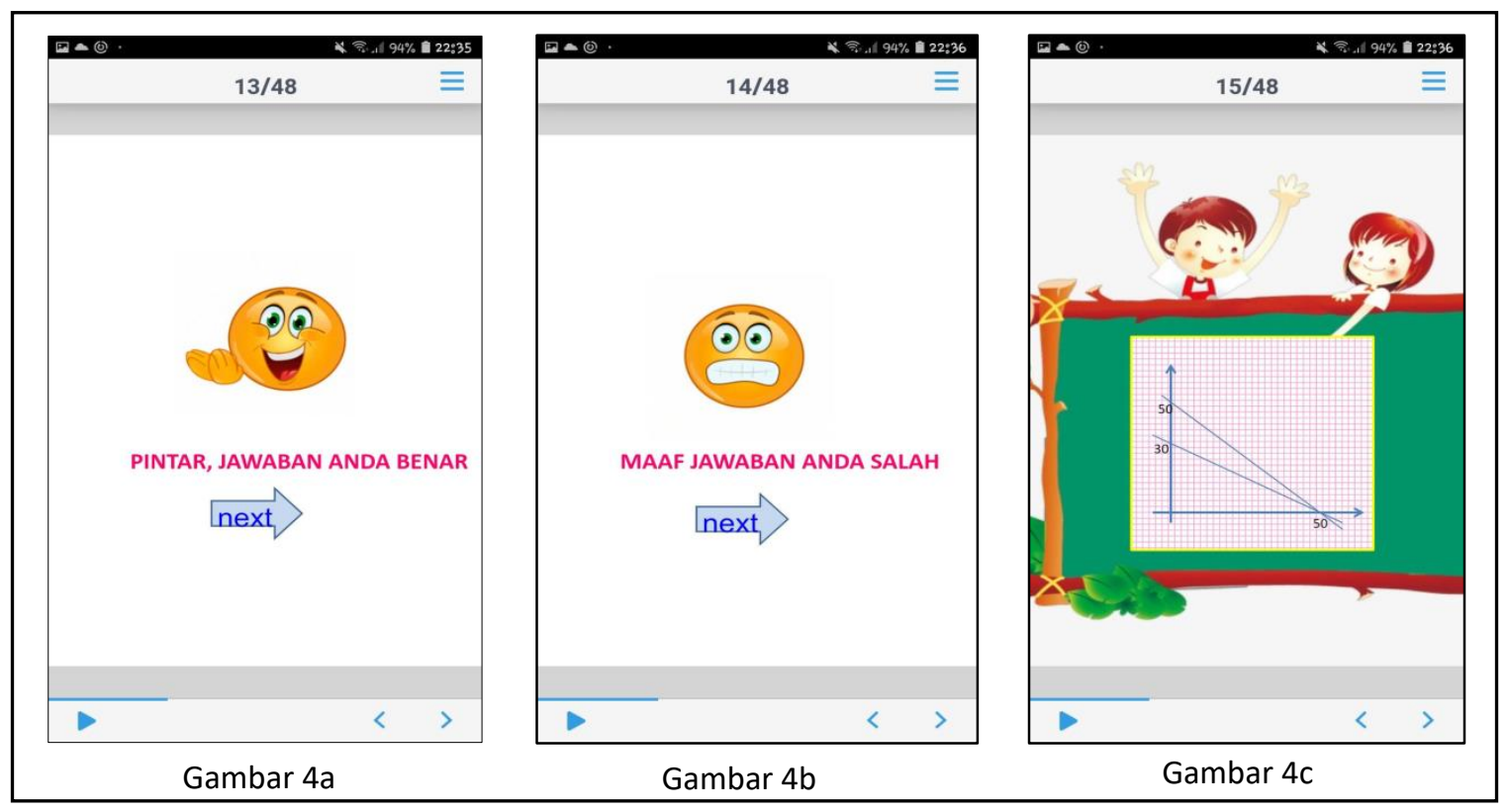

Gambar 4. Tampilan jawaban benar (4a), jawaban salah (4b), dan keterangan jawaban yang benar (4c)

Setiap pilihan jawaban di-hiperlink. Setelah siswa menjawab pertayaan akan muncul seperti yang ditunjukkan pada Gambar 4. Jika jawaban benar muncul Gambar 4a dan jika jawaban salah muncul Gambar 4b. Pada tekan tombol next maka akan muncul jawaban yang benar pada Gambar 4c.

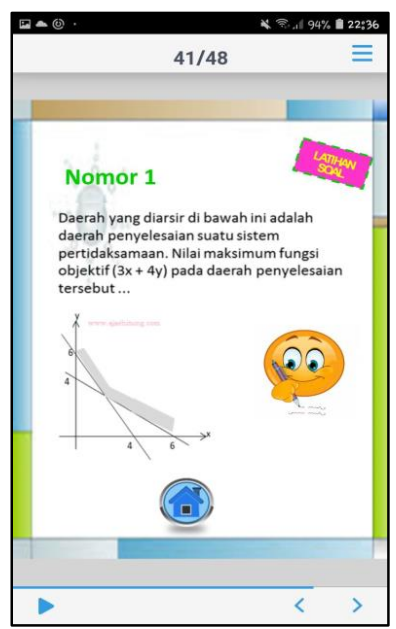

Gambar 5. Latihan soal

Gambar 5 merupakan salah satu latihan soal yang diberikan pada media ini. Pada menu latihan soal terdapat 5 soal uraian program linier. Soal yang diberikan mengarah pada latihan soal kontekstual sesuai kompetensi dasar yang diberikan. 
c. Uji coba produk

Setelah produk awal selesai dikembangkan, dilakukan uji coba yang terdiri dari dua tahap, yaitu uji ahli dan uji coba skala kecil. Uji ahli atau validasi terdiri dari validasi media dan validasi materi. Hasil penilaian validator terhadap media dapat dilihat pada Tabel 1 berikut.

Tabel 1. Hasil validasi media

\begin{tabular}{lc}
\hline Kriteria aspek yang dinilai & $\begin{array}{c}\text { Skor rata-rata tiap } \\
\text { aspek }\end{array}$ \\
\hline Isi media pembelajaran & 3,2 \\
Gambar dan animasi & 3,5 \\
Kegunaan media pembelajaran & 3,3 \\
Bentuk dan tampilan & 3,0 \\
Bahasa dan simbol & 3,0 \\
Skor Kevalidan & 3,2 \\
\hline
\end{tabular}

Berdasarkan Tabel 1 bahwa skor kevalidan yang diperoleh dari hasil validasi yaitu 3,2. Berdasarkan skor tersebut menunjukkan bahwa media pembelajaran E-Modul ini sudah valid. Namun menurut validator ahli, E-Modul ini akan lebih bagus lagi apabila interaktifnya ditambah.

\section{Hasil dan Pembahasan}

Berdasarkan hasil validasi dan uji coba media pembelajaran E-Modul ini sudah valid. Skor setiap aspeknya dinilai $\geq 3$ dan rata-ratanya 3,2 dari skala tertinggi 4 .

Tabel 2. Kriteria hasil validasi instrumen

\begin{tabular}{cl}
\hline \multicolumn{1}{c}{ Interval } & \multicolumn{1}{c}{ Kategori } \\
\hline $3,25 \leq \mathrm{SR} \leq 4,00$ & Sangat valid \\
\hline $2,50 \leq \mathrm{SR}<3,25$ & Valid \\
\hline $1,75 \leq \mathrm{SR}<2,50$ & Kurang valid \\
\hline $0,00 \leq \mathrm{SR}<4,00$ & Tidak valid \\
\hline
\end{tabular}

(Diadopsi dari Arikunto, 2013:89)

Hasil uji coba E-Modul yang dikembangkan dengan skala kecil memberikan respon positif terhadap aspek yang dinilai. Aspek yang dinilai diantaranya mengenai isi media pembelajaran, kegunaan media pembelajaran, serta bentuk dan tampilan media pembelajaran, Hasil uji coba ini menunjukkan bahwa E-Modul yang dikembangkan dapat menambah motivasi siswa belajar program linier. Sehingga siswa sekolah menengah dapat memahami konsep program linier dan dapat menyelesaikan masalah kontekstual mengenai program linier.

E-Modul yang dikembangkan secara umum memiliki kelebihan yaitu 1) tampilannya memuat gambar dan animasi yang menarik sesuai dengan konsep, 2) menu pemahaman konsep dibuat interaktif sehingga siswa terlibat dalam penemuan konsep, 3) pemahaman konsep 
menggunakan masalah kontekstual agar siswa mudah memahami dalam contoh nyata dalam kehidupan sehari-hari, 4) media ini merupakan media yang dapat dimasukkan dalam handphone sehingga lebih praktis untuk dibawa. Namun E-Modul ini juga memiliki kekurangan yaitu 1) interaktifnya perlu ditambah, 2) jumlah soal latihan masih terbatas, 3) media ini belum ada audionya.

\section{Simpulan}

E-Modul yang dikembangkan sudah valid dan mampu memotivasi siswa untuk belajar matematika. Beberapa saran untuk pengembangan media selanjutnya yaitu: (1) E-Modul yang dikembangkan pada penelitian ini masih pada materi program linier, sehingga pada pengembangan selanjutnya diharapkan pada materi lain, (2) Interaktif dari pengembangan EModul seperti ini bisa ditambah sehingga siswa lebih banyak berperan aktif dalam pembelajaran menggunakan E-Modul ini, dan (3) E-Modul yang akan dikembangkan dapat ditambah dengan audio agar lebih menarik.

\section{Daftar Rujukan}

Afgani, M. W., \& Si, M. (2008). Pengembangan Media Website Pembelajaran. Jurnal Pendidikan Matematika, 2, 15.

Ariawan, B. (2015). Menyelesaikan Permasalahan Program Llinear Menggunakan Geogebra. 18.

Arikunto, Suharsimi. 2013. Dasar-dasar Evaluasi Pendidikan (Edisi Kedua). Jakarta: PT Bumi Aksara.

Arsyad, A. (2015). Media pembelajaran (Edisi Revisi). Jakarta: Rajawali Pers.

Booth, J. L., Barbieri, C., Eyer, F., \& Pare-Blagoev, E. J. (2014). Persistent and Pernicious Errors in Algebraic Problem Solving. The Journal of Problem Solving, 7(1). https://doi.org/10.7771/1932-6246.1161

Dabbagh, N., \& Kitsantas, A. (2012). Personal Learning Environments, social media, and selfregulated learning: A natural formula for connecting formal and informal learning. The Internet and Higher Education, 15(1), 3-8. https:/ / doi.org/10.1016/j.iheduc.2011.06.002

Dorko, A., \& Speer, N. M. (2013). Calculus Students' Understanding of Volume. Investigations in Mathematics Learning, 6(2), 48-68. https:/ / doi.org/10.1080/24727466.2013.11790332

Greenhow, C., \& Lewin, C. (2016). Social media and education: Reconceptualizing the boundaries of formal and informal learning. Learning, Media and Technology, 41(1), 6-30. https://doi.org/10.1080/17439884.2015.1064954

Hidayat, R., \& Iksan, Z. H. (2015). The Effect of Realistic Mathematic Education on Students' Conceptual Understanding of Linear Progamming. 8.

Kamber, D., \& Takaci, D. (2018). On problematic aspects in learning trigonometry. International Journal of Mathematical Education in Science and Technology, 49(2), 161-175. https://doi.org/10.1080/0020739X.2017.1357846

Kennedy, L. M., Tipps, S., \& Johnson, A. (2008). Guiding children's learning of mathematics (11th ed). Belmont, CA: Thomson/Wadsworth. 
Mulyana, R. 2004. Mengartikulasikan Pendidikan Nilai. Bandung: Alfabeta

National Council of Teachers of Mathematics, \& NCTM (Ed.). (2000). Principles and standards for school mathematics. Reston, VA: National Council of Teachers of Mathematics.

Permendikbud Nomor 24 Tahun 2016 Lampiran 2016 tentang Kompetensi Inti dan Kompetensi Dasar Pelajaran pada Kurikulum 2013 pada Pendidikan Dasar dan Pendidikan Menengah

Permendikbud Nomor 158 Tahun 2014 tentang Penyelenggaraan Sistem Kredit Semester (SKS) pada jenjang SMP/MTS dan SMA/SMK/MA/MAK

Putra, A.R. (2015). Pengembangan media pembelajaran matematika berbantuan computer berbasis kontruktivis untuk kelas X SMK pada materi geometri. (Tesis Program Pascasarjana. Universitas Negeri Malang)

Septian, A. D., \& Chandra, T. D. (2016). Defragmentasi Struktur Berpikir Siswa Impulsif dalam Menyelesaikan Soal Cerita. 18.

Serhan, D. (2015). Students' Understanding of the Definite Integral Concept. International Journal of Research in Education and Science, 1(1), 84. https:/ / doi.org/10.21890/ijres.00515

Setyadi, D. (2017). Pengembangan Mobile Learning Berbasis Android Sebagai Sarana Berlatih Mengerjakan Soal Matematika. Satya Widya, 33(2), 87-92. https://doi.org/10.24246/j.sw.2017.v33.i2.p87-92

Uno, H. B. 2008. Model Pembelajaran Menciptakan Proses Belajar Mengajar yang Kreatif dan Efektif. Jakarta: Bumi Aksara.

Veloo, A., Krishnasamy, H. N., \& Wan Abdullah, W. S. (2015). Types of Student Errors in Mathematical Symbols, Graphs and Problem-Solving. Asian Social Science, 11(15), p324. https://doi.org/10.5539/ass.v11n15p324

Zuana, M. (2018). ALSUNA: Journal of Arabic and English Language e-ISSN:2615-0905. Digital Storytelling, 1, 14. 